Research Article

\title{
Numerical Investigation and Mold Optimization of the Automobile Coat Rack Compression Molding
}

\author{
Youmin Wang, Xiangli Li $\mathbb{D}$, and He Sui \\ School of Mechanical Engineering, Anhui Polytechnic University, Wuhu, Anhui 241000, China \\ Correspondence should be addressed to Xiangli Li; 2190130114@stu.ahpu.edu.cn
}

Received 29 December 2020; Revised 7 April 2021; Accepted 20 April 2021; Published 30 April 2021

Academic Editor: Ashwini Kumar

Copyright ( 2021 Youmin Wang et al. This is an open access article distributed under the Creative Commons Attribution License, which permits unrestricted use, distribution, and reproduction in any medium, provided the original work is properly cited.

In order to have more accurate control over the compression molding of automobile coat rack, improve the quality of molding products, and achieve the goal of lightweight design, a novel mechanical model for the main two-layer composite structure of the coat rack is proposed. In this regard, the main factors affecting the mechanical properties of the composite structure are obtained. The hot air convection is selected for the sheet preheating. During the experiment, the hot air temperature, preheating time, molding pressure, and pressing holding time are set to $250^{\circ} \mathrm{C}, 110 \mathrm{~s}, 13 \mathrm{MPa}$, and $80 \mathrm{~s}$, respectively. Moreover, the error compensation method is applied to compensate for the shrinkage of the product during solidification and cooling. The LS-DYNA finite element software is used to simulate the molding process of the main body of the coat rack, and the node force information with large deformation is obtained accordingly. The load mapping is used as the boundary condition of mold topology optimization, and the compression molding of the main body of the coat rack is optimized. A lightweight design process and method for the compression molding of automotive interior parts and a mathematical model for the optimization of the solid isotropic material penalty (SIMP) (power law) material interpolation of the concave and convex molds are established. Based on the variable density method, OptiStruct is used for the lightweight design of the convex and concave molds of the main body of the coat rack, which reduces the mold weight by $15.6 \%$ and meets the requirements of production quality and lightweight.

\section{Introduction}

Car coat rack is defined as a vehicle accessory to provide beautiful coverage and protection for the covered area or system. In addition, it is an important acoustic component for blocking noise from the luggage compartment. Accordingly, the car coat rack has been widely used in almost all vehicles. With the increasing integration of automobile functions, the coat rack has become a carrier for many other parts. Recently, improving the molding quality of automotive interior parts has focused on controlling the mechanical properties of products, the optimal combination of process parameters, and mold optimization. More specifically, Zheng et al. [1] performed CAE analysis and physical tests on coat racks to find control parameters that affect the product strength and the load capacity. Moreover, they considered the requirements of product appearance and obtained optimal control parameter values to achieve the design goals, including low-cost and high-performance products. However, the mechanical properties of the material and the mechanical model of the coat rack were not considered. Guo et al. [2] proposed a method for the recycling felt waste of PP glass fiber composite and studied the impact of the size of crushed particles and the proportion of crushed material on the formability and mechanical properties of the coat rack. However, the thickness impact of the glass fiber sheet on the mechanical properties of the material was not considered so that the formulation of process parameters was not reliable. Miao et al. [3] discussed the effect of the multicomponent fiber composition process on the performance of the car coat rack. Through investigating the ratio, pressure, temperature, and speed of multicomponent fibers, the orthogonal test was carried out to find the best component. Studies showed that the combination scheme is an effective way to produce car coat racks and investigate all aspects of their performance. However, 
the experimental method was not used to calculate the material shrinkage so that the solidification shrinkage and the product cooling were not compensated. Yu [4] simulated, analyzed, and performed experiments on the nonwoven fabric hot-molding mold and the molding process and showed that the molding temperature is the most influential factor in the hot-molding process. Moreover, the temperature distribution was studied, which solved the problem of repeatedly adjusting the molding temperature based on experience, but the number of research objects and simulation experiments was small. Shao [5] optimized the process parameters of glass mat reinforced thermoplastics (GMT) composite material compression molding and obtained the optimal combination from the theoretical point of view. In this optimization, no analysis software was applied to optimize the mold. Demirci and Yildiz [6] studied the effect of conventional steel, new generation DP-TRIP steels, AA7108-AA7003 aluminum alloys, AM60-AZ31 magnesium alloys, and crash-box cross-sections on crash performance of thin-walled energy absorbers which are investigated numerically for the lightweight design of vehicle structures. However, it does not involve numerical research on nonmetallic materials such as car coat racks. It is worth noting that none of the foregoing studies has simulated the compression molding, while the molding simulation can accurately evaluate the correlation between level factors and the mold quality. In order to resolve this shortcoming, it was intended to investigate the mechanical properties of thermoplastic composite materials and design the car coat structure. In this regard, the LS-DYNA finite element software was applied to simulate the molding process, and the load mapping was used as the boundary condition for mold topology optimization. Finally, mold structure optimization was established and the mold structure was optimized to improve the molding quality of the coat rack.

\section{Investigating the Mechanical Properties and Structural Design of Thermoplastic Composites for Automobile Coat Racks}

In this section, it is intended to establish a mechanical model for the thermoplastic composite of the car coat rack (the mechanical model is solved), analyze some test cases, determine the thickness of the main body, complete the formulation of the main body molding process parameters, determine the shrinkage compensation value, and calculate the heat transfer in the cooling system. These items are discussed in detail in the following.

\subsection{Establishment of Structural Mechanical Model for GMT/} PET Composite. In the present paper, the composite two-layer structure is taken as the research object. The upper layer is a decorative layer, the main specimen is made of needle-punched PET fabric, and the lower layer is a GMT sheet. It should be indicated that the mechanical properties of GMT sheet depend on the spatial distribution of the fiber and PP and the combination between them [7]. In the composite structure, the materials, thickness, and other physical parameters of the upper and lower layers are different. Accordingly, the composite plate is regarded as a thin plate, and then its mechanical model is established by considering variations of different physical parameters along the $Z$-axis. Figure 1 shows the mechanical model of the composite structure.

In order to simplify the mechanical model and the corresponding solving method, it is assumed that the glass fiber and PP materials are evenly dispersed into the space occupied by the sheet, and the overall material performance is linearly combined by the volume fraction of each component. Under a specific glass fiber mass fraction, the GMT sheet has a specific material constant, which can be simplified to an isotropic material in the analysis.

The volume fraction of PP and glass fiber in the GMT sheet can be expressed as follows:

$$
\begin{aligned}
& V_{p}=\frac{\rho_{1} \cdot M_{p}}{\rho_{p}}, \\
& V_{b}=\frac{\rho_{1} \cdot M_{b}}{\rho_{b}},
\end{aligned}
$$

where $\rho_{1}, \rho_{p}$, and $\rho_{b}$ are the total density of GMT sheets, the bulk density of polypropylene, and glass fiber at room temperature, respectively. Moreover, $M_{p}$ and $M_{b}$ denote the mass ratio of polypropylene and glass fiber, respectively. Then the material constant of the GMT sheet can be calculated. It is worth noting that the sum of quality scores satisfies the following expression:

$$
M_{b}+M_{p}=1 \text {. }
$$

Since the GMT sheet may contain air and cavities during the molding process, the sum of the practical volume fraction of glass fiber and $\mathrm{PP}$ is

$$
V_{b}+V_{p} \leq 1
$$

Moreover, the void volume rate is defined as

$$
V_{c}=1-\left(V_{p}+V_{b}\right)=1-\frac{\rho_{1} \cdot M_{b}}{\rho_{p}}-\frac{\rho_{1} \cdot M_{b}}{\rho_{b}}
$$

Let the physical property parameter of the GMT sheet be $P$, where $P$ can represent the elastic modulus of the material $E$, Poisson's ratio $\mu$, linear expansion coefficient $\alpha$, and so on. Then this parameter in the composite is defined as follows [8]:

$$
P=P_{p} \cdot V_{p}+P_{b} \cdot V_{b}
$$

where $P_{p}$ and $P_{b}$ are the physical properties of polypropylene and glass fiber, respectively. Similarly, the elastic modulus and Poisson's ratio of the GMT sheet can be calculated from equations (6) and (7), respectively.

$$
\begin{aligned}
& E_{1}=E_{p} \cdot V_{p}+E_{b} \cdot V_{b}, \\
& \mu_{1}=\mu_{p} \cdot V_{p}+\mu_{b} \cdot V_{b},
\end{aligned}
$$

where $E_{p}$ and $E_{b}$ are the elastic modulus of polypropylene and glass fiber, respectively. Moreover, $\mu_{p}$ and $\mu_{b}$ are 


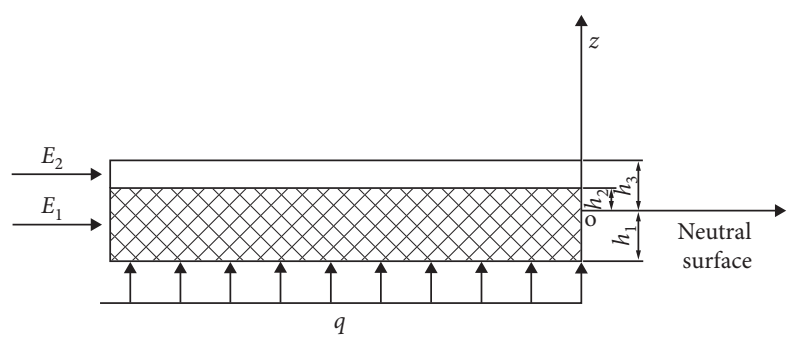

FIGURE 1: Mechanical model of the composite structure.

Poisson's ratio of polypropylene and glass fiber, respectively. The upper layer is a single material of needle-punched PET fabric, so the elastic modulus and Poisson's ratio are $E_{2}$ and $\mu_{2}$. Then the elastic modulus of the two-layer composite structure is divided into two layers:

$$
E(z)= \begin{cases}E_{1}, & \left(-h_{1}, h_{2}\right), \\ E_{2}, & \left(h_{2}, h_{3}\right) .\end{cases}
$$

The same operation can be conducted for Poisson's ratio in the following form:

$$
\mu(z)= \begin{cases}\mu_{1}, & \left(-h_{1}, h_{2}\right), \\ \mu_{2}, & \left(h_{2}, h_{3}\right) .\end{cases}
$$

The differential equation of the elastic surface of the thin plate can be expressed in the following form:

$$
D \nabla^{4} w=q,
$$

where $D$ is the bending stiffness of the sheet, $D=E h^{3} / 12\left(1-\mu^{2}\right)$, and $h$ is the total thickness of the sheet. The left side of equation (10) $D \nabla^{4} w$ denotes the elastic resistance per unit area, and $w$ is the deflection. Moreover, the left side $q$ is the lateral load per unit area. The stress differential equation can be simplified as follows:

$$
\frac{\partial \sigma_{Z}}{\sigma_{Z}}=\frac{E(z)}{2 \cdot\left(1-\mu(z)^{2}\right)} \cdot\left(\frac{h^{2}}{4}-z^{2}\right) \cdot \nabla^{4} w .
$$

Integrating both sides with respect to $z$ from $-h_{1}$ to $h_{3}$ yields the following expressions:

$$
\begin{gathered}
\int_{-h_{1}}^{h_{3}} \frac{\partial \sigma_{Z}}{\sigma_{Z}} \mathrm{~d} z=\sigma_{Z} \mid \frac{h_{3}}{-h_{1}}=0-q=-q, \\
\int_{-h_{1}}^{h_{3}} \frac{E(z)}{2\left(1-\mu(z)^{2}\right)}\left(\frac{h^{2}}{4}-z^{2}\right) \nabla^{4} w \mathrm{~d} z=\int_{-h_{1}}^{h_{3}} \frac{E(z)}{2\left(1-\mu(z)^{2}\right)}\left(\frac{h^{2}}{4}-z^{2}\right) \mathrm{d} z \nabla^{4} w .
\end{gathered}
$$

In order to simplify expressions, parameter $D$ is defined as follows:

$$
D=-\int_{-h_{1}}^{h_{3}} \frac{E(z)}{2\left(1-\mu(z)^{2}\right)}\left(\frac{h^{2}}{4}-z^{2}\right) \mathrm{d} z .
$$

Then the integral can be decomposed into the sum of integrals of each layer:

$$
\begin{aligned}
-D= & \int_{-h_{1}}^{h_{2}} \frac{E(z)}{2\left(1-\mu(z)^{2}\right)}\left(\frac{h^{2}}{4}-z^{2}\right) \mathrm{d} z+\int_{h_{2}}^{h_{3}} \frac{E(z)}{2\left(1-\mu(z)^{2}\right)} \\
& \cdot\left(\frac{h^{2}}{4}-z^{2}\right) \mathrm{d} z=-D_{1}-D_{2} .
\end{aligned}
$$

2.2. The Mechanical Model of the Composite Structure Is Solved. When solving the thin plate deflection-bending problem by the Navier method, the deflection $w$ should be initially obtained from the elastic surface differential equation under the boundary conditions of the plate edge [9].

During the unsupported subsidence, the length and width for a rectangular thin plate, which is simply supported on four sides, are $a$ and $b$, respectively. In this case, the boundary conditions are

$$
\left.\begin{array}{l}
(w)_{x=0}=0,\left(\frac{\partial^{2} w}{\partial x^{2}}\right)_{x=0}=0 \\
(w)_{x=a}=0,\left(\frac{\partial^{2} w}{\partial x^{2}}\right)_{x=a}=0 \\
(w)_{y=0}=0,\left(\frac{\partial^{2} w}{\partial x^{2}}\right)_{y=0}=0 \\
(w)_{y=b}=0,\left(\frac{\partial^{2} w}{\partial x^{2}}\right)_{y=b}=0
\end{array}\right\}
$$


The deflection $w$ can be calculated from the following trigonometric series:

$w=\sum_{m=1}^{\infty} \sum_{n=1}^{\infty} w_{m}=\sum_{m=1}^{\infty} \sum_{n=1}^{\infty} A_{m n} \sin \frac{m \pi x}{a} \sin \frac{n \pi y}{b}$,

where $m$ and $n$ are positive integers. Substitute this expression into equation (15) which indicates that all boundary conditions are satisfied. In order to find the coefficient $A_{m n}$, equation (16) is introduced into equation (10):

$$
\pi^{4} D \sum_{m=1}^{\infty} \sum_{n=1}^{\infty}\left(\frac{m^{2}}{a_{2}}+\frac{n^{2}}{b^{2}}\right) A_{m n} \sin \frac{m \pi x}{a} \sin \frac{n \pi y}{b}=q
$$

and expanding the load $q$ on the right side of equation (17) into a multiple triangle series results in the following expression:

$$
q=\sum_{m=1}^{\infty} \sum_{n=1}^{\infty} A_{m n} \sin \frac{m \pi x}{a} \sin \frac{n \pi y}{b},
$$

where $A$ can be solved through the method of determining the triangle series, and the solution is

$$
\begin{aligned}
& A_{m n}=\frac{16 q_{0}}{\pi^{6} m n D\left(\left(m^{2} / a^{2}\right)+\left(n^{2}\right.\right.} \\
& \text { can be applied to calculate } \\
& \qquad \frac{\sin (m \pi x / a) \sin (n \pi y / b)}{m n\left(\left(m^{2} / a^{2}\right)+\left(n^{2} / b^{2}\right)\right)^{2}}
\end{aligned}
$$

Internal forces can be expressed in the following form:

$$
\left\{\begin{array}{l}
M_{x}=-D\left(\frac{\partial^{2} w}{\partial x^{2}}+\mu \frac{\partial^{2} w}{\partial y^{2}}\right) \\
M_{y}=-D\left(\frac{\partial^{2} w}{\partial y^{2}}+\mu \frac{\partial^{2} w}{\partial x^{2}}\right) \\
M_{x y}=M_{y x}=-D(1-\mu) \frac{\partial^{2} w}{\partial x \partial y} \\
F_{S, x}=-D(1-\mu) \frac{\partial^{2}}{\partial x} \nabla^{2} w \\
F_{S, y}=-D(1-\mu) \frac{\partial^{2}}{\partial y} \nabla^{2} w
\end{array}\right.
$$

Based on the performed calculations and analyses, the two-layer composite structure is simply supported on four sides, where the length $a$, width $b$, and GMT sheet thickness are $0.1 \mathrm{~m}, 0.1 \mathrm{~m}$, and $3.5 \mathrm{~mm}$, respectively. Moreover, the

$$
A_{m n}=\frac{4}{a b} \int_{0}^{a} \int_{0}^{b} q(x, y) \sin \frac{n \pi y}{b} \sin \frac{m \pi x}{b} \mathrm{~d} x \mathrm{~d} y .
$$
form:

Then equation (18) can be rewritten in the following

$$
\begin{aligned}
q= & \frac{4}{a b} \sum_{m=1}^{\infty} \sum_{m=1}^{\infty} \frac{4}{a b} \int_{0}^{a} \int_{0}^{b} q(x, y) \sin \frac{n \pi y}{b} \sin \frac{m \pi x}{b} \mathrm{~d} x \mathrm{~d} y \\
& \cdot \sin \frac{n \pi y}{b} \sin \frac{m \pi x}{b}
\end{aligned}
$$

$A_{m n}=\frac{4 \int_{0}^{a} \int_{0}^{b} q(x, y) \sin (n \pi y / b) \sin (m \pi x / b) \mathrm{d} x \mathrm{~d} y}{\pi^{4} a b D\left(\left(m^{2} / a^{2}\right)+\left(n^{2} / b^{2}\right)\right) .}$

When the thin plate is subjected to a uniform load, $q$ becomes a constant $q_{0}$. Under this circumstance, equation (21) can be rewritten in the following form:

$(m=1,3,5, \ldots ; n=1,3,5, \ldots)$

composite density is $1.3 \mathrm{~g} / \mathrm{cm}^{3}$ and the void ratio is assumed to be 0 . The mass fraction and density of the glass fiber are $30 \%$ and $2.6 \mathrm{~g} / \mathrm{cm}^{3}$, respectively. In the present study, alkalifree fibers $(E)$ with an elastic modulus of $72 \mathrm{GPa}$ and Poisson's ratio of 0.2 are applied. Furthermore, the density, elastic modulus, and Poisson's ratio of PP are $0.93 \mathrm{~g} / \mathrm{cm}^{3}$, $1.4 \mathrm{GPa}$, and 0.4 , respectively. The lateral uniform load is $10 \mathrm{MPa}$, the thickness of the transition layer is $1.5 \mathrm{~mm}$, and the specimen is made of needle-punched PET with an elastic modulus of $4000 \mathrm{MPa}$.

Based on the established mathematical model, the thickness impact on the mechanical properties of the thin plate can be investigated by changing the thickness of the GMT sheet under the condition that the glass fiber content is maintained 30\%, while the applied load and constraints remain constant. The iterative calculations are performed in the MATLAB environment. The maximum deflection and stress value of the two-layer structure are shown in Table 1. The stress value can be obtained from the internal force value through the generalized Hook definition of the thin plate.

Table 1 indicates that, for a constant load and constraint, as the thickness of the GMT sheet increases, the deflection of the two-layer composite structure gradually decreases, thereby reducing the normal stress and the shear force. It is inferred that, as the sheet thickness increases, flexural, tensile, and shear resistance of the whole plate improve.

When the thickness is fixed and different glass fiber ratios are used, the deflection and internal force of the plate are shown in Table 2. 
TABle 1: Maximum deflection and stress values for different thicknesses.

\begin{tabular}{lccc}
\hline GMT plate thickness $(\mathrm{mm})$ & $\begin{array}{c}\text { Deflection } \\
(\mathrm{m})\end{array}$ & $\sigma_{x}, \sigma_{y}(\mathrm{~Pa})$ & $\begin{array}{c}\tau_{x y}, \tau_{y x} \\
(\mathrm{~Pa})\end{array}$ \\
\hline 3.3 & 0.0022899 & 34.914 & 24.598 \\
3.4 & 0.0019380 & 30.428 & 21.478 \\
3.5 & 0.0016547 & 26.357 & 18.759 \\
3.6 & 0.0014242 & 23.458 & 16.102 \\
3.7 & 0.0011984 & 19.857 & 13.478 \\
\hline
\end{tabular}

Table 2 indicates that, under the condition of unchanged load and restraint, as the content of glass fiber increases, the deflection value and bending moment value decrease, while the corresponding torque increases. Therefore, the optimal content of GMT sheet glass fiber is selected according to the required mechanical performance index.

2.3. Thickness of the Car Coat Rack. Based on the foregoing discussions, it is concluded that the rigidity design requirements can be achieved by increasing the thickness of the GMT sheet without changing the main structure of the car coat rack. However, the material consumption for too thick products cannot be justified. More specifically, the production cost increases, the product becomes prone to stress concentration, and the molding quality reduces.

The stiffness test principle is as follows: as a support frame, the sample deflects continuously at the midpoint of the span until the fracture or deformation reaches a certain predefined value. In this process, the applied stress to the sample is measured. Figure 2 illustrates the schematic configuration of composite layers, indicating that the composite consists of a PET fabric and the GMT sheet.

Since the fabric and the substrate are subjected to stress in parallel, the mixed law of elastic modulus of the parallel composite structure can be used [9]:

$$
E_{0}=E_{1} V_{1}+E_{2} V_{2}
$$

where $E_{0}, E_{1}$, and $E_{2}$ denote the elastic modulus of the composite material, PP glass fiberboard, and PET fabric, respectively. Substituting equations (6) into (25) gives

$$
E_{0}=\left(E_{p} V_{p}+E_{b} V_{b}\right) V_{1}+E_{2} V_{2}
$$

Then the predicted value of the elastic modulus in the composite shown in Figure 2 can be expressed in the following form:

$$
E_{0}=\left(E_{p} V_{p}+E_{b} V_{b}\right) \frac{d_{1}}{d_{1}+d_{2}}+E_{2} \frac{d_{2}}{d_{1}+d_{2}},
$$

where $d_{1}$ and $d_{2}$ denote the thickness of PP glass fiber and PET fabric, respectively. In order to meet the rigidity design requirements, the following conditions should be satisfied:

$$
\begin{aligned}
E_{0} I \geq \sigma, \\
I=\frac{b \cdot\left(d_{1}+d_{2}\right)^{3}}{12},
\end{aligned}
$$

where $\sigma$ is the required stiffness; $I$ is the moment of inertia; and $b$ is the width of the coat rack. In order to solve the equations easily, a thick needle-punched PET fabric with a thickness of $1.5 \mathrm{~mm}$, elastic modulus of $4000 \mathrm{MPa}$ is considered in the calculations, and GMT sheet porosity is assumed to be 0 . The glass fiber is made of alkali-free fiber (E) with an elastic modulus of $72 \mathrm{GPa}$, while the elastic modulus of PP is $1.4 \mathrm{GPa}$. Moreover, the coat rack width $b$ is $600 \mathrm{~mm}$ and the required bending stiffness is $\sigma \geq 60 \mathrm{~N} /$ $\mathrm{mm}^{2}$.

The combination of glass fiber content and thickness of the GMT sheet that satisfy the stiffness requirements can be calculated from equations (27) and (28). The proposed combination is shown in Table 3.

Based on the obtained results, a glass fiber content of $30 \%$ and a thickness of $4.5 \mathrm{~mm}$ is proposed as the selected composition. To maximize the safety factor, the thickness of the GMT sheet is rounded to $4.5 \mathrm{~mm}$. Since the thicknesses of the GMT sheet and PET fabric are $4.5 \mathrm{~mm}$ and $1.5 \mathrm{~mm}$, the overall thickness of the composite is $6 \mathrm{~mm}$.

2.4. Formulation of the Process Parameters to Mold the Main Body of the Automobile Coat Rack. By analyzing the common quality defects and causes of the main body of the coat rack, the main processing parameters that affect the molding process of the car coat rack are determined. These parameters are the molding pressure, holding time, and the molding temperature.

2.4.1. Sheet Warm-Up Time. In order to heat the GMT sheet, hot air convection preheating is used. In this case, the sheet can be expanded to 2-3 times the thickness of the cold sheet. It should be indicated that the sheet temperature should be less than $230^{\circ} \mathrm{C}$; otherwise, the PP polypropylene will degrade, thereby affecting the surface of the molded product and reducing the heat resistance and strength of the product $[10,11]$. The preheating time of the GMT sheet can be calculated through the following expression [12] (29):

$$
t=70.9521+0.2318 d-0.2810 T,
$$

where $t$ is the appropriate preheating time, min; $d$ is the sheet thickness, $\mathrm{mm}$; and $\mathrm{T}$ is the hot air temperature, ${ }^{\circ} \mathrm{C}$.

During the experiment, hot air flow from an oven is used to preheat the sheet. The thickness of the GMT sheet is $4.5 \mathrm{~mm}$ and the preheating temperature of the hot air is $250^{\circ} \mathrm{C}$. Based on equation (29), the preheating time is adjusted to $99 \mathrm{~s}$. In the experiment, the sheet is taken out of the oven and transferred to the mold. Since the temperatures of the material and the oven reduce during the material transfer, the preheating time of the sheet is set to $110 \mathrm{~s}$. 
TABLe 2: Deflection and internal force values for different glass fiber contents.

\begin{tabular}{lccc}
\hline GMT plate glass fiber content $(\%)$ & Deflection $(\mathrm{mm})$ & Bending moment $(\mathrm{N} \cdot \mathrm{m})$ & Torque $(\mathrm{N} \cdot \mathrm{m})$ \\
\hline 25 & 0.0016732 & 25.434 & 29.562 \\
30 & 0.0016547 & 25.293 & 29.646 \\
35 & 0.0016238 & 25.177 & 29.739 \\
40 & 0.0015966 & 25.054 & 29.822 \\
45 & 0.0015624 & 24.964 & 29.018 \\
\hline
\end{tabular}

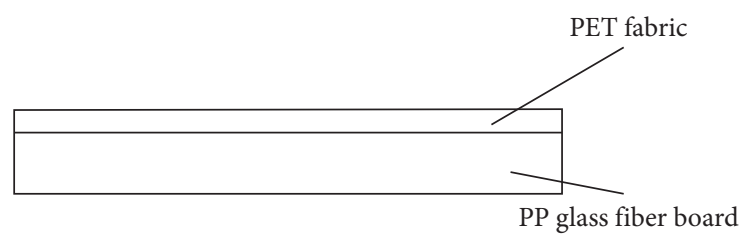

Figure 2: Schematic configurations of the composite layers.

TABle 3: Proposed GMT sheet glass fiber ratio and thickness combination.

\begin{tabular}{lcc}
\hline GMT sheet glass fiber content (\%) & GMT sheet thickness $(\mathrm{mm})$ & Round thickness $(\mathrm{mm})$ \\
\hline 20 & 4.886 & 5 \\
25 & 4.636 & 4.8 \\
30 & 4.386 & 4.5 \\
35 & 4.136 & 4.3 \\
40 & 3.886 & 4 \\
\hline
\end{tabular}

2.4.2. Molding Pressure and Mold Clamping Speed. Appropriate molding pressure not only improved the product quality but also made up for the shortage if other industrial parameters were not adequate [13].

(1) The method of maximum gauge pressure:

$$
f_{\text {table }}=\frac{f_{1} f_{2} S}{T}
$$

where $f_{\text {table }}, f_{1}$, and $f_{2}$ denote the gauge pressure, unit pressure required by the product, and the rated gauge pressure of the press, respectively. Meanwhile, $S$ and $T$ denote the projected area of the product in the compression direction and the pressing force, respectively.

$$
x=\frac{f_{1} S}{T}
$$

where $x$ is the ratio of the force acting on the pressure direction of the product to the pressing force. When $x>1$, the pressing force is too small to meet the production requirements. On the other hand, when $x<1$, the pressing force is sufficient to meet the production demand.

(2) The method of Piston area method:

$$
f_{\text {table }}=\frac{f_{1} S}{F}
$$

where $F$ is the cross-sectional area of the piston of the press.
In the present study, for a four-post-servo-hydraulic machine (model; company) with $F=0.5 \mathrm{~m}^{2}$ and $S=0.84 \mathrm{~m}^{2}$, the molding pressure is $13 \mathrm{MPa}$ and $f_{\text {table }}=22 \mathrm{MPa}$. For these parameters, equation (31) indicates that $x>1$, so that the selected hydraulic pressure meets the molding requirements.

In the molding process to produce the main body of the automobile coat rack, the mold clamping speed is not a fixed value. It should be indicated that the molding process can be divided into 5 main stages:

(1) When the sheet is placed in the mold, the concave mold decreases at a speed of $60 \mathrm{~mm} / \mathrm{s}$.

(2) The interval between the convex and concave mold gradually decreases. Consequently, when the guide column enters the guide sleeve, the speed becomes $8 \mathrm{~mm} / \mathrm{s}$. Moreover, when the convex and concave molds are closed, the sheet is molded under pressure.

(3) Cooling and solidification.

(4) After holding the pressure for $80 \mathrm{~s}$, the concave mold is split at a speed of $8 \mathrm{~mm} / \mathrm{s}$.

(6) After the split mold is completed, the concave mold is $60 \mathrm{~mm} / \mathrm{s}$. Then the speed rises and when the die is reset, the product is removed.

These five stages are also shown in Figure 3.

2.4.3. Holding Time. The cooling time calculation results are utilized as a reference to select the holding time. For large products such as car coat racks, the length and width are far 


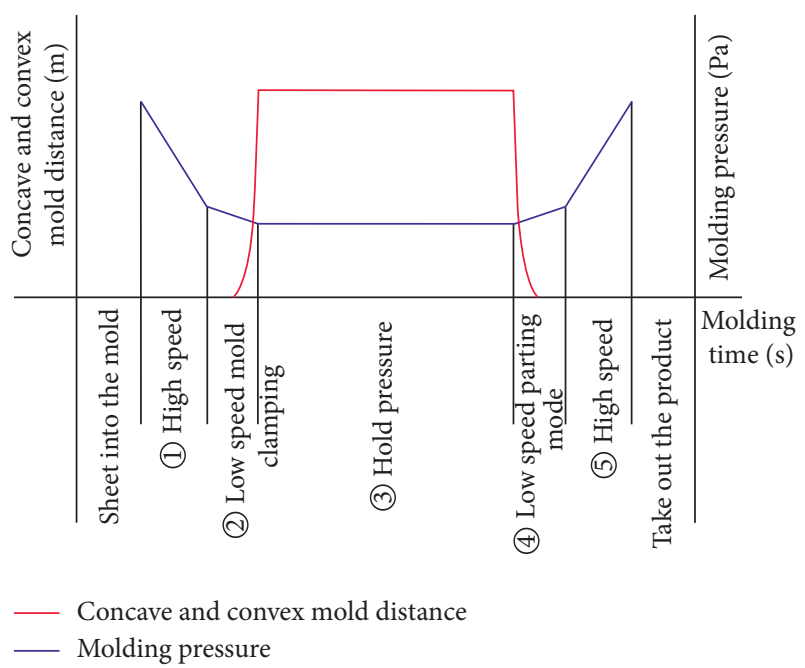

FIgURE 3: Speed variation graph during the mold clamping.

beyond their thickness, and they have two-dimensional characteristics. However, the heat is only transferred in the one-dimensional direction, that is, the thickness direction of the part. Therefore, the cooling of such products can be conducted as follows.

Heat transfer can be calculated from the following expression:

$$
\frac{\partial T}{\partial \theta^{\prime}}=k \frac{\partial^{2} T}{\partial^{2} x^{2}}
$$

where $T$ and $k$ denote the average temperature when the sheet is demolded and the thermal diffusion coefficient of the sheet, respectively.

In order to separate the variables, the following equation is used:

$$
\begin{aligned}
\theta^{\prime} & =-\left(\frac{2}{\pi}\right)^{2} \frac{x_{1}^{2}}{k} \ln \left[\frac{\pi\left(T-T_{w}\right)}{T_{0}-T_{w}}\right], \\
k & =\frac{\lambda}{\rho \cdot c_{p}},
\end{aligned}
$$

where $x_{1}$ is half the thickness of the part, $m ; T_{w}$ is the mold cavity temperature, ${ }^{\circ} \mathrm{C} ; T_{0}$ is the sheet molding temperature, ${ }^{\circ} \mathrm{C} ; \rho$ is the density of the sheet, $\mathrm{kg} / \mathrm{m}^{3} ; \lambda$ is the thermal conductivity of the sheet, $\mathrm{kW} / \mathrm{m} \cdot{ }^{\circ} \mathrm{C}$; and $c_{p}$ is the specific heat capacity of the sheet, $\mathrm{kJ} / \mathrm{kg} \cdot{ }^{\circ} \mathrm{C}$.

The process parameter values are shown in Table 4.

Substituting the abovementioned parameters into equation (34), the cooling time of the molding of the main body of the automobile coat rack is mathematically expressed as follows:

$$
\begin{aligned}
& k=\frac{0.33 \times 10^{-3}}{1130 \times 1550 \times 10^{-3}}=1.88 \times 10^{-7}, \\
& t=-\left(\frac{2}{\pi}\right)^{2} \frac{0.00225^{2}}{k} \ln \left[\frac{\pi(80-40)}{4(220-40)}\right] \approx 74 \mathrm{~s} .
\end{aligned}
$$

Combining with the previous pressure holding time, the pressure holding time is determined to be $80 \mathrm{~s}$.
TABLE 4: The value of process parameters.

\begin{tabular}{lc}
\hline Parameter name & Value \\
\hline $\begin{array}{l}\text { The thickness of the main body of the car coat rack } \\
(\mathrm{mm})\end{array}$ & 4.5 \\
The average temperature of the mold cavity wall $T_{w}$ & 40 \\
$\left({ }^{\circ} \mathrm{C}\right)$ & 220 \\
The molding temperature $T_{0}\left({ }^{\circ} \mathrm{C}\right)$ & 80 \\
The average temperature when the sheet is demolded & \\
$T\left({ }^{\circ} \mathrm{C}\right)$ & 1130 \\
The density of the sheet $\rho\left(\mathrm{kg} / \mathrm{m}^{3}\right)$ & 1.55 \\
The specific heat capacity of the sheet $c_{p}\left(\mathrm{~kJ} / \mathrm{kg} \cdot{ }^{\circ} \mathrm{C}\right)$ & $0.33 \times 10^{-3}$ \\
The thermal conductivity of the sheet $\lambda\left(\mathrm{kW} / \mathrm{m} \cdot{ }^{\circ} \mathrm{C}\right)$ & 0.3
\end{tabular}

2.5. Shrinkage Compensation Value. The molding shrinkage rate of the product is measured experimentally. The experimental process is as follows: the main model of the coat rack of the reference model is selected. Moreover, 20 pieces of GMT plates with a thickness of $4.5 \mathrm{~mm}$ glass fiber content of $30 \%$ and a needle-punched PET fabric of $1.5 \mathrm{~mm}$ thickness are selected. It should be indicated that, in the experiment, the sheet preheating time, the pressure holding time, molding pressure, and mold closing speed utilize the abovementioned parameters. When the mold is opened, the distance between the selected positioning points is measured, and each piece is averaged at one measurement in the length and width directions. After the product is left at room temperature for 24 hours, the selected positioning point is measured again, using equation (29). Finally, the average shrinkage rate of the composite two-layer structure of GMT sheet + needle-punched PET fabric is $0.354 \%$.

2.6. Heat Transfer Calculation for the Cooling System of the Automobile Coat Rack Compression Molding Mold. The cooling system adopts the water cooling method, and a cooling water channel is laid on the mold surface to pass the cooling water. In this section, the design and calculation of the cooling system of the forming mold of the main body of the car coat rack are established.

2.6.1. The Total Heat of the Sheet into the Cavity. In a molding process, the total heat transferred from the sheet to the mold is mathematically expressed as follows:

$$
Q_{1}=C_{p} \cdot\left(T_{0}-T\right) \cdot V \cdot \rho,
$$

where $T_{0}$ and $T$ denote the sheet molding temperature and the average temperature when the sheet is demolded, respectively. Moreover, $\rho, c_{p}$, and $V$ are the density of the sheet, the specific heat capacity of the sheet, and the volume of the sheet, respectively. It is worth noting that the volume of the sheet is set to $1.4 \mathrm{~m} \times 0.6 \mathrm{~m} \times 0.0045 \mathrm{~m}$.

2.6.2. Heat Taken away by the Cooling Water. The heat taken away by the mold cooling water in one press molding is expressed as follows:

$$
Q_{2}=Q_{1}-Q_{c}-Q_{R}-Q_{L},
$$


where $Q_{c}, Q_{R}$, and $Q_{L}$ denote the convection heat transfer from the mold to the air, the radiation heat transfer from the mold to the air, and the heat transfer from the mold to the hydraulic machine through the upper and lower mold bases, respectively.

Under normal circumstances, $90 \%-95 \%$ of the heat brought into the sheet can be taken away by the cooling water through the mold cooling channel. Therefore, during the design process, $Q_{2}=Q_{1}$.

Since the main body of the car coat rack is a large thinwalled product, it can be designed according to $50 \%$ of the heat taken by the concave mold and the convex mold; then,

$$
Q_{2 a}=Q_{2 t}=0.5 Q_{2} \text {. }
$$

2.6.3. Cooling Water Hole Diameter. The volume flow of the cooling water can be calculated according to equation (39) during the molding process of the die and the die of the die in one molding process:

$$
\left\{\begin{array}{l}
V_{2 a}=\frac{Q_{2 a}}{\rho_{1} c_{1}\left(\theta_{1}-\theta_{2}\right) \cdot t}, \\
V_{2 t}=\frac{Q_{2 t}}{\rho_{1} c_{1}\left(\theta_{1}-\theta_{2}\right) \cdot t},
\end{array}\right.
$$

where $\theta_{1}$ and $\theta_{2}$ are the inlet and outlet temperatures of the mold cooling water, respectively. It should be indicated that the temperature difference should not be too large and its maximum value should not exceed $5^{\circ} \mathrm{C}$. Moreover, $V$ $\left(\mathrm{m}^{3} \cdot \mathrm{min}^{-1}\right)$ and $\rho_{1}\left(\mathrm{~kg} / \mathrm{m}^{3}\right)$ denote the volume flow of cooling water and the density of water, respectively. Furthermore, $c_{1}\left(\mathrm{~kJ} / \mathrm{kg} \cdot{ }^{\circ} \mathrm{C}\right)$ and $t(\mathrm{~min})$ are the specific heat capacity of water and the cooling time of one molding, respectively.

The density of water is $1000 \mathrm{~kg} / \mathrm{m}^{3}$, and the specific heat capacity of water is $4.2 \mathrm{~kJ} / \mathrm{kg} \cdot{ }^{\circ} \mathrm{C}$, which is calculated according to equations (36) and (38):

$$
\begin{aligned}
V_{2 a} & =V_{2 t}=\frac{0.5 Q_{2}}{\rho_{1} c_{1}\left(\theta_{1}-\theta_{2}\right) \cdot t}=\frac{0.5 \cdot C_{p} \cdot\left(T_{0}-T\right) \cdot V \cdot \rho}{\rho_{1} c_{1}\left(\theta_{1}-\theta_{2}\right) \cdot t} \\
& =16.275 \mathrm{~m}^{3} / \mathrm{min} .
\end{aligned}
$$

According to the correlation between the cooling water pipe volume flow and the pipe diameter, the cooling water pipe diameter is determined as $D=27 \mathrm{~mm}$.

The correlation between the distance $P$ of the cooling water pipe, the distance $H$ from the profile, and the diameter $D$ of the channel is $P=(3 \sim 5) \quad D, H=(1 \sim 2) D$; from $D=27 \mathrm{~mm}$, take the pipe distance $P=80 \mathrm{~mm}, H=30 \mathrm{~mm}$.

\section{Simulation of the Molding Process}

In the present study, the Ls-Dyna finite element program is used to simulate the molding process of the main body of the car coat rack to obtain the nodal force information of the stress concentration area of the mold during the molding process [14]. Therefore, the boundary conditions for the topological optimization of the convex and concave mold are obtained. Moreover, the design of the mold is optimized.

3.1. The Main Influencing Factors of the Modeling Process. The molding process is a complicated nonlinear challenging process. The influencing factors in this process include the compression molding of the sheet, the elastic deformation of the mold under high temperature and high pressure, and the frictional contact between the mold and the sheet during the mold clamping process; it is a complex finite element problem of thermal and mechanical coupling [15].

3.1.1. Grid Division. The density distribution of the grid is one of the important factors that affect the calculation accuracy [16]. In order to simplify the meshing and improve the quality and solution rate of meshing, the CATIA software is utilized to simplify the model in the early stage. The convex and concave molds use sweeping meshing, SOLID168 elements are used to mesh, and the length direction is divided into 60 . It should be indicated that the width direction is divided into 3 equal parts with a total of 942,000 units. The sheet adopts shell163 thin shell unit and the sheet grid is a regular quadrilateral unit with 15000 units. Moreover, the unit has 11 different algorithms. In the present study, the Belytschko - Tsay algorithm is used because its calculation speed is high. Figure 4 illustrates the grid division diagram.

3.1.2. Heat Transfer Model Settings. According to the characteristics of the molding process, the following two heat transfer methods are described:

(1) Radiation and air-cooling heat exchange

Owing to the small proportion of the air-cooled heat transfer, air-cooling and radiation can be written as a unified heat transfer equation [17]:

$$
q=\left(h_{1}+h_{2}\right)\left(T-T_{0}\right)
$$

where $q$ is the heat flux, density, $\mathrm{J} / \mathrm{m}^{2} \cdot \mathrm{s}$. Moreover, $h_{1}$ and $h_{2}$ denote the convective heat transfer coefficient, $\mathrm{W} / \mathrm{m}^{2} \cdot \mathrm{K}$, and the radiant heat transfer coefficient, $\mathrm{W} / \mathrm{m}^{2} \cdot \mathrm{K}$, respectively.

$$
h_{2}=\varepsilon \delta\left(T+T_{0}\right)\left(T^{2}-T_{0}^{2}\right) \text {, }
$$

where $\varepsilon$ and $\delta$ are the blackness coefficient and the Boltzmann constant, $\mathrm{J} / \mathrm{K}$, respectively. Moreover, $T$ and $T_{0}$ are the surface temperature of the sheet, ${ }^{\circ} \mathrm{C}$, and the ambient temperature, ${ }^{\circ} \mathrm{C}$, respectively.

Table 5 presents the specific values.

(2) Contact heat transfer

A contact heat transfer exists between the sheet and the mold, and calculation of the contact heat transfer 


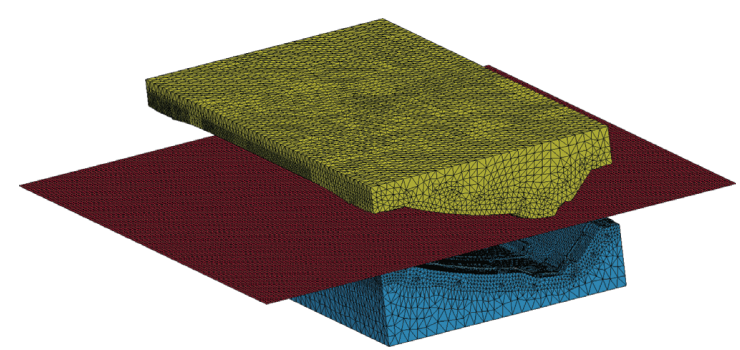

FIGURE 4: Grid division diagram.

TABle 5: Heat transfer constant.

\begin{tabular}{lcccc}
\hline$h_{1}+h_{2}$ & $\varepsilon$ & $\delta$ & $T$ & $T_{0}$ \\
\hline $200 \mathrm{~W} /\left(\mathrm{m}^{2} \cdot \mathrm{K}\right)$ & 0.6 & $5.672 \times 10^{-8} \mathrm{~J} / \mathrm{K}$ & $220^{\circ} \mathrm{C}$ & $20^{\circ} \mathrm{C}$ \\
\hline
\end{tabular}

is challenging. Empirical equation [18] (43) is used in this regard:

$$
q=h_{\text {cond }}\left(T-T_{1}\right)
$$

In the abovementioned equation, $h_{\text {cond }}=K / l_{\text {gap }}$, where $K=10$ and $l_{\text {gap }}$ is the contact gap between the workpiece and the mold, which is automatically calculated in the LS-DYNA program, and its unit is $\mathrm{mm}$. Moreover, $T_{1}$ denotes the mold cavity temperature, ${ }^{\circ} \mathrm{C}$.

3.1.3. Contact and Friction Settings. The keyword *CONTACT_FORMING_ONE_WAY_SURFACE_TO_SURFACE_THERMAL defines the contact method of the compression molding, and FORMING_ONE_WAY is the type of contact specifically used for molding. It should be indicated that the penalty function algorithm is used to calculate the contact interface force. Since LS-DYNA is originally used for the collision analysis, if it is used for the forming analysis, the default parameter settings should be modified [19]. In the present study, the penalty function stiffness factor SLSFAC is modified to 0.1.

In the compression molding process, there is friction between the mold and the sheet. Therefore, the friction coefficient should be determined. In LS-DYNA, the friction force is calculated by the Coulomb model. In this study, the average friction coefficient is 0.1 .

3.1.4. Hourglass Control. In order to verify the validity of the calculation result, the ratio of the hourglass energy to total energy should be less than $10 \%$. On the other hand, the hourglass control coefficient cannot be too large. When the hourglass control coefficient is greater than 0.15 , the calculation will be unstable. Therefore, the hourglass control sets $I H Q=4$, and the hourglass energy coefficient is set to $\mathrm{QH}=0.1$.

3.1.5. Energy Dissipation Control. In the numerical simulation of the compression molding, the main reference index to determine the accuracy of the simulation result is the change in energy. The control of energy is set by the keyword ${ }^{*}$ CONTROL_ENERGY. In this study, set $\mathrm{HGEN}=2$, RWEN $=2, \operatorname{SLNTEN}=2$, and RYLEN $=2$. The purpose of the abovementioned setting is to consider various energy dissipations in the energy balance.

3.1.6. Control of the Time Step. In the LS-DYNA software, the convergence of the time integration algorithm is conditional, and it is stable only when the time step $\Delta t$ is less than the critical time step, which is mathematically expressed as

$$
\begin{aligned}
& \Delta t<\frac{\Delta l}{c+\dot{x}}, \\
& c=\sqrt{\frac{E}{\left(1-v^{2}\right) \cdot \rho}},
\end{aligned}
$$

where $\Delta l, c$, and $x$ denote the characteristic length of the element, $m$, the sound velocity of the material, $\mathrm{m} / \mathrm{s}$, and the velocity of the node, $\mathrm{m} / \mathrm{s}$, respectively.

In the compression molding simulation, as time passes, the deformation increases. Then, $\Delta t$ quickly decreases, indicating that the integration algorithm divergence interrupts the simulation. In order to avoid this phenomenon, the mass scaling technique is used to set a duration value $\Delta t_{s z}$ through the keyword *CONTROL_TIMESTEP. In the simulation, if $\Delta t<\Delta t_{s z}$, the program automatically increases the density of the structural material and the time step size. In the present study, $\Delta t_{s z}$ is set as 0.0000025 , time step size scaling factor TSSFAC $=0.9$, and DTINIT $=0$. Moreover, the initial step size is set by the program.

\subsection{Setting of Materials and Boundary Conditions}

(1) Material: the sheet material is selected from the constitutive equation of the thermoplastic material. The thickness of the sheet is defined by the actual thickness of the part. The material of the convex and concave mold is 45\#. The sheet is made of PP-based GMT composite material with a glass fiber content of $30 \%$.

(2) Initial boundary conditions: the initial process parameters of the automobile coat rack compression molding are set as follows. Moreover, the punch is set to fix the lower table of the hydraulic press, and the concave mold should be closed under the pressure of the press. The molding pressure is set to $13 \mathrm{MPa}$, the mold closing speed after the upper mold contacts the sheet is $8 \mathrm{~mm} / \mathrm{s}$, and the initial temperature of the sheet is $220^{\circ} \mathrm{C}$. The mold temperature is $40^{\circ} \mathrm{C}$, the cooling channel water temperature is $20^{\circ} \mathrm{C}$, and the pressure holding time is $80 \mathrm{~s}$.

3.3. Finite Element Numerical Calculation Results. Figures 5-7 show the numerical simulation results in the molding process, which are obtained after the software calculation. 
Time $=1.2199$

Contours of effective stress $(v-m)$

Reference shell surface

Min $=0$, at elem\# 466963

Max $=345$, at elem\# 78093

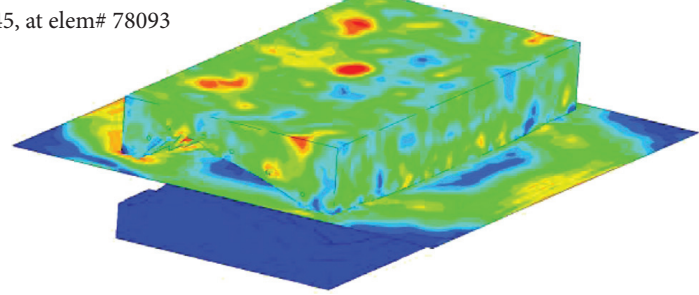

(a)

Time $=3.6599$

Contours of effective stress $(v-m)$

Reference shell surface

Min $=0.0779287$, at elem\# 804289

Max $=345$, at elem\# 75756

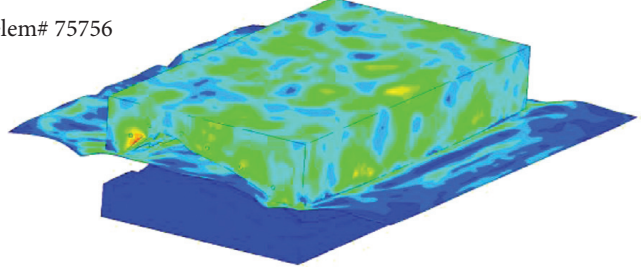

(c)

Time $=7.9299$

Contours of effective stress $(v-m)$

Reference shell surface

Min $=0.0533153$, at elem\# 513264

Max $=345$, at elem\# 11392

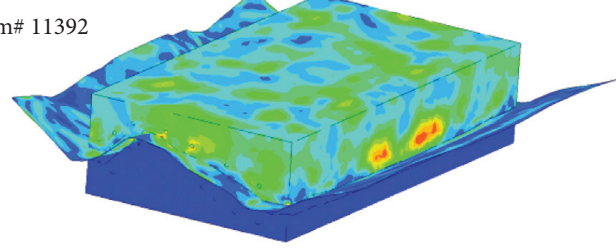

(e)
Time $=2.44$

Contours of effective stress $(v-m)$

Reference shell surface

Min $=0.0906078$, at elem $\# 801032$

Max $=345$, at elem\# 12265

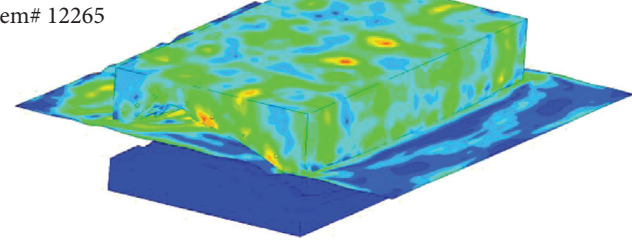

(b)

Time $=5.7947$

Contours of effective stress $(v-m)$

Reference shell surface

Min $=0.0725777$, at elem\# 798571

Max $=345$, at elem\# 52086

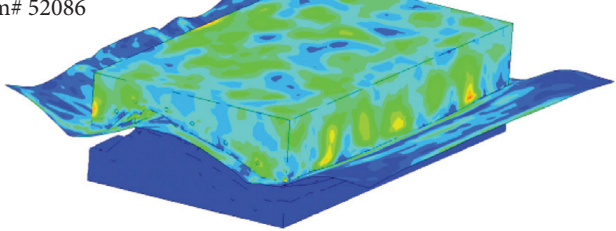

(d)

Time $=9.4549$

Contours of effective stress $(v-m)$

Reference shell surface

Min $=0.0829849$, at elem \# 885116

Max $=711.588$, at elem\# 909186

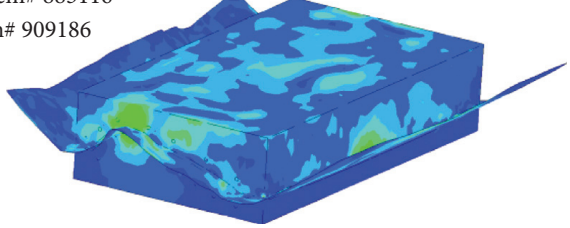

(f)

Figure 5: The equivalent stress diagram of the forming process.

Time $=14.335$

Contours of effective stress $(v-m)$

Reference shell surface

$\operatorname{Min}=3.63642$, at elem\# 876981

$\mathrm{Max}=345.001$, at elem $\# 741474$

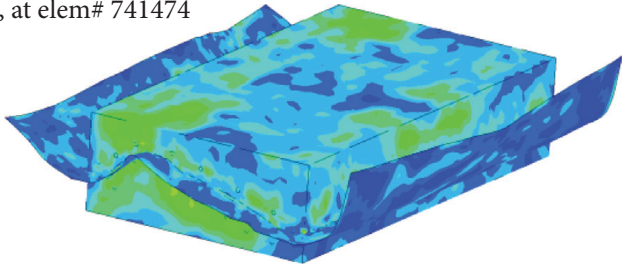

(a)
Time $=28.365$

Contours of effective stress $(v-m)$

Reference shell surface

Min $=1.06772$, at elem\# 747972

$\operatorname{Max}=345$, at elem\# 189378

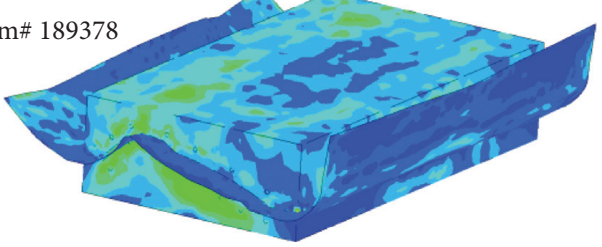

(b)

Figure 6: Continued. 
Time $=19.215$

Contours of effective stress $(v-m)$

Reference shell surface

Min $=2.89149$, at elem\# 13894

$\operatorname{Max}=345$, at elem\# 151856

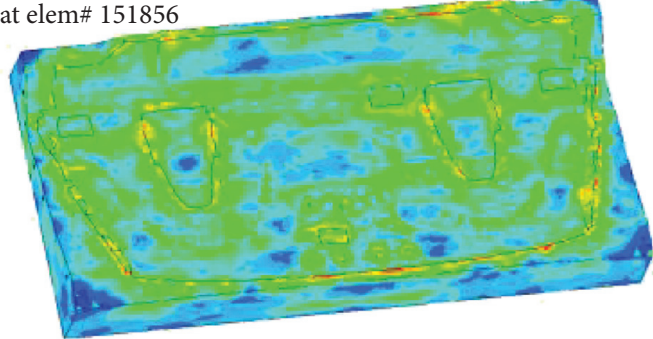

(c)

Time $=52.155$

Contours of effective stress $(v-m)$

Reference shell surface

Min $=0.766231$, at elem $\# 536714$

$\operatorname{Max}=345.001$, at elem\# 487450

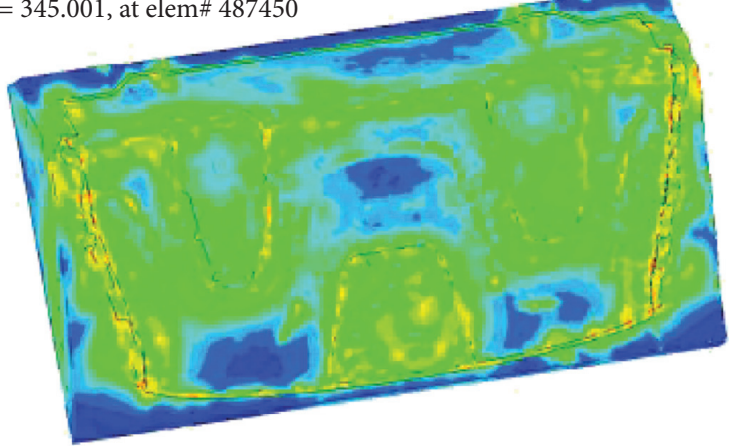

(e)
Time $=43.005$

Contours of effective stress $(v-m)$

Reference shell surface

Min $=2.45393$, at elem\# 13429

Max $=341.061$, at elem\# 283299

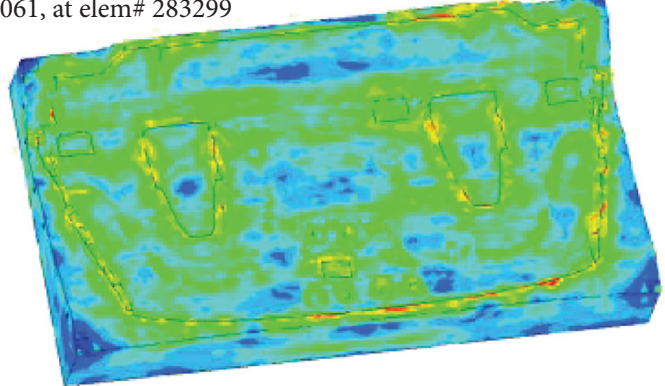

(d)

Time $=57.34$

Contours of effective stress $(v-m)$

Reference shell surface

$\operatorname{Min}=0.527726$, at elem\# 536714

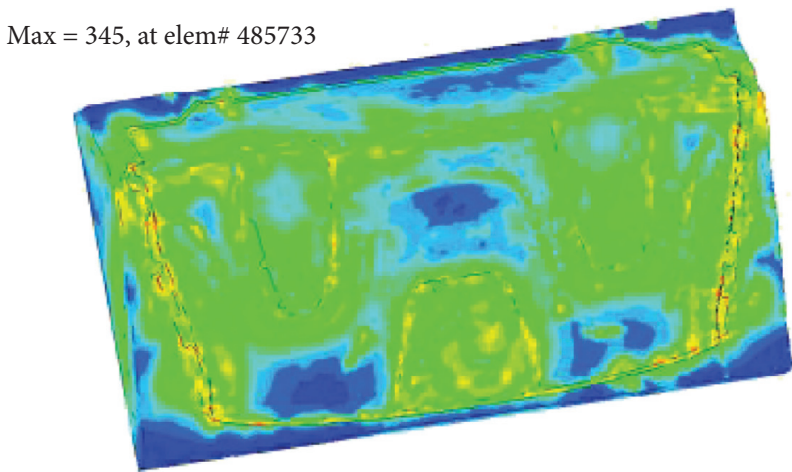

(f)

Figure 6: Cloud diagram of stress changes during the packing process.

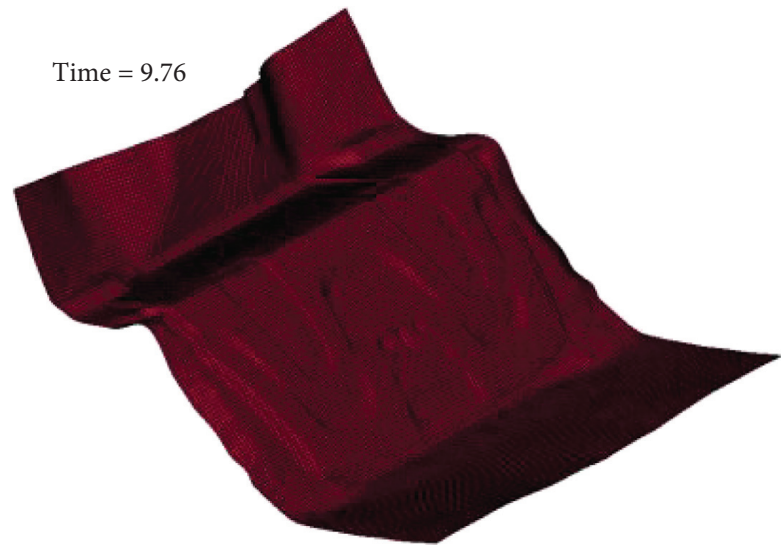

(a)

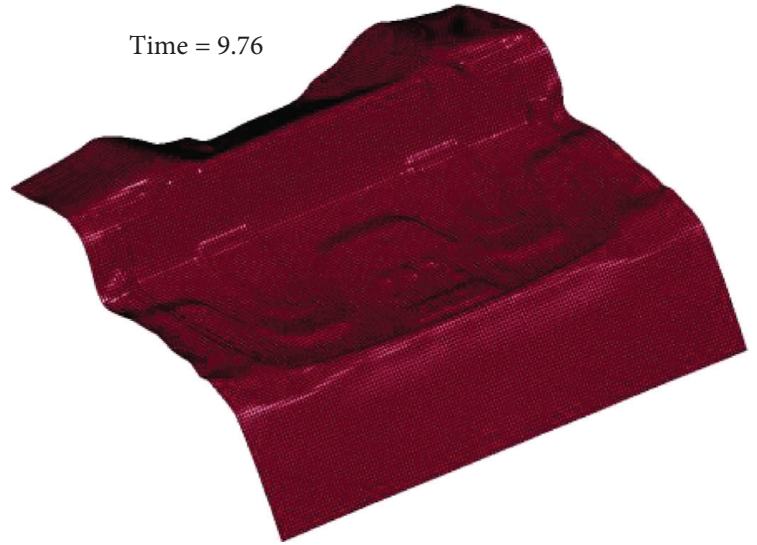

(b)

FIGURE 7: The main body shape of the car coat rack. 
3.3.1. Equivalent Stress during Forming. The simulation results of the equivalent stress during the molding process show that, during the molding process of the main body of the automobile coat rack, the stress concentration area is located at the outer contour of the mold and the slope is steeper.

3.3.2. Equivalent Stress during the Holding Pressure. The simulation results of the equivalent stress during the packing process show that the node displacement is the largest when the packing time is $11 \mathrm{~s}$. As the packing time passes, the mold temperature decreases and the deformation gradually decreases too. After $64 \mathrm{~s}$, it remains unchanged until the end of the packing process.

3.3.3. Appearance of the Molding Process. The abovementioned simulation results show that the nodal force information of the mold during the compression molding process is obtained. Therefore, the load mapping is used as the boundary condition for the next topology optimization.

\section{Optimized Mold Design}

Currently, the lightweight design of molds is the development direction of mold optimization [20]. Based on the empirical design, CAE tools are used to perform mold structure analysis and optimization design before processing. Aiming at the problem of excessive quality of molds and due to the current empirical design of compression molding dies for automotive interior parts, in the present study, a lightweight design process and method is proposed for compression molding dies.

4.1. Lightweight Design Process of the Mold Structure. According to the numerical simulation method for the molding process of automotive interior parts and the topology optimization theory of the variable density method [21], a lightweight design method for the mold structure of interior parts molding is proposed.

(1) According to the mold design requirements, the structure of the compression molding convex and concave mold is designed in accordance with the traditional mold design guidelines.

(2) With the help of the LS-DYNA finite element program, the compression molding process of the main body of the coat rack is numerically simulated to obtain the force information of the convex and concave mold nodes in the actual working conditions.

(3) Load mapping is used to construct convex and concave boundary conditions of die structure optimization.

(4) The improvement space of the mold structure design is clarified, and the design area and nondesign area are determined.
(5) Based on the OptiStruct, the topological optimization of the convex-concave structure is iteratively solved.

(6) The final shape is optimized according to the topology of the convex and concave mold structure, and the three-dimensional software is utilized to redesign the mold structure.

(7) According to the redesigned mold structure for mold processing and manufacturing.

4.2. OptiStruct-Based Optimization Design of the Mold Topology. OptiStruct uses LS-DYNA for preprocessing and definition of structural optimization problems. After completing the finite element modeling in LS-DYNA, the optimization definition panel is used to define optimization variables, constraints and goals, and optimization parameters. Then, OptiStruct is submitted for structural analysis and optimization. Figure 8 shows the OptiStruct structure optimization design flowchart [22].

4.2.1. The Establishment of the Topological Optimization Model of the Mold Convex and Concave Mold Structure. In the optimization process of the convex and concave dies, the problem of the mass minimization can be equated to the problem of the volume minimization. The real working conditions of the convex and concave molds are analyzed. Moreover, based on the solid isotropic material penalty (SIMP) method and according to the numerical simulation calculation results of the compression molding, the maximum displacement of the nodes in the stress concentration area is used as the constraint condition. Furthermore, the material element density is used as the design variable. The minimum volume of the convex-concave structure is the SIMP optimization model [23], and the density penalty factor $P$ is set to 3 . The model is formulas (45) and (46),

$$
\begin{aligned}
& \left\{\begin{array}{l}
E_{e}=\rho_{e}^{p} \cdot E_{0}, \\
0<\rho_{\min } \leq \rho_{e} \leq 1,
\end{array}\right. \\
& \left\{\begin{array}{l}
\min : V \\
\text { subject to: } K U=F, \\
0<\rho_{\min } \leq \rho_{e} \leq 1, \\
U_{j} \leq U_{j}^{*},
\end{array}\right.
\end{aligned}
$$

where $\rho_{i}$ are $V$ denote the design variable for the topology optimization with the variable density method and the overall structure volume, respectively. Moreover, $U, K$, and $F$ are the overall displacement column vector, the overall structure stiffness matrix, and the external load vector, respectively.

4.2.2. Topological Optimization of Convex and Concave Dies Structure. According to the analysis of the real working conditions of the convex and concave molds, based on the SIMP material interpolation optimization model of the convex and concave molds, OptiStruct is used to solve. 


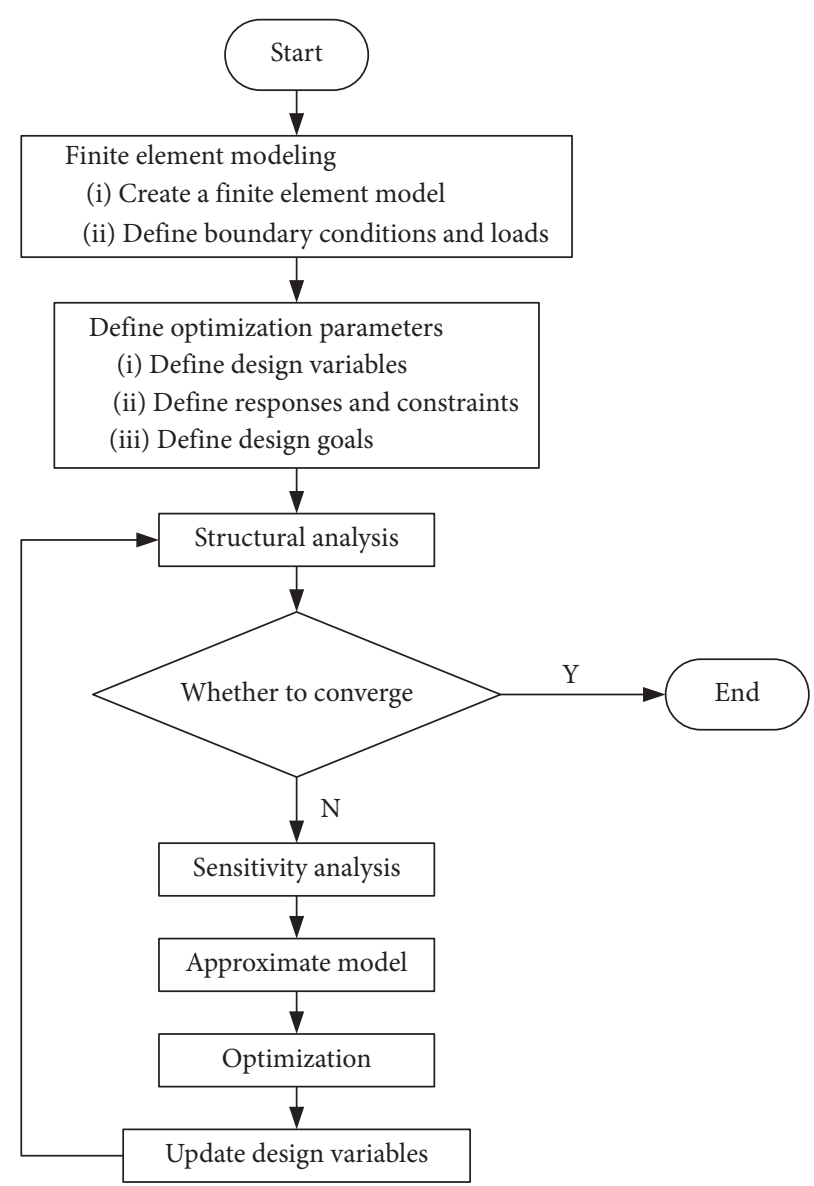

FIgURE 8: Topology optimization flowchart.

OptiStruct describes the three elements of the optimal design through different types of information cards.

\section{(1) Set optimization variables}

In the topology optimization of convex and concave molds, the tighter the optimized cell density is, the more important the material is. Moreover, this should be retained when redesigning the convex and concave mold structure [24]. As it tends to 0, it can be determined according to the analysis of the convex and concave structure. Therefore, the design area and nondesign area should be selected when designing optimization variables.

(2) Define optimization goals and constraints

Through the numerical simulation of the molding process of the main body of the car coat rack, the node number of the stress concentration and deformation of the mold during the molding process are obtained. Moreover, the number and displacement values with time change are obtained by applying LS-Prepositi postprocessing. Export as a .txt file, and define the corresponding node displacement load in Hyperworks according to these results, in order to optimize the mold design. Figure 9 shows the nodal displacement results derived from the concave and convex molds.
Figures 10 and 11 show that boundary conditions are applied and the optimization area is determined. The analysis of the mold structure shows that, in the optimized design, the concave and convex model surfaces and the location of the cooling water channel will remain unchanged. Moreover, the design area and the nondesign area are divided according to this, and the pink area of the concave mold is determined as the nondesign area. Furthermore, the blue part is the design area, the light color of the punch is the nondesign area, and the dark color is the design area. The boundary conditions are as described above.

(3) Trial calculation

The preliminary trial calculation is passed, as shown in Figure 12, through the topology optimization algorithm and through the iterative calculation of this process to find the best path for load transfer, to obtain the optimal solution for topology optimization, and thus to obtain the best distribution of convex and concave mold materials.

(4) Topology optimization results

After the lamination calculation, the topological results of the die and punch of the die are obtained. Figure 13 illustrates a topographic cloud image with a density threshold of 0.2 . 


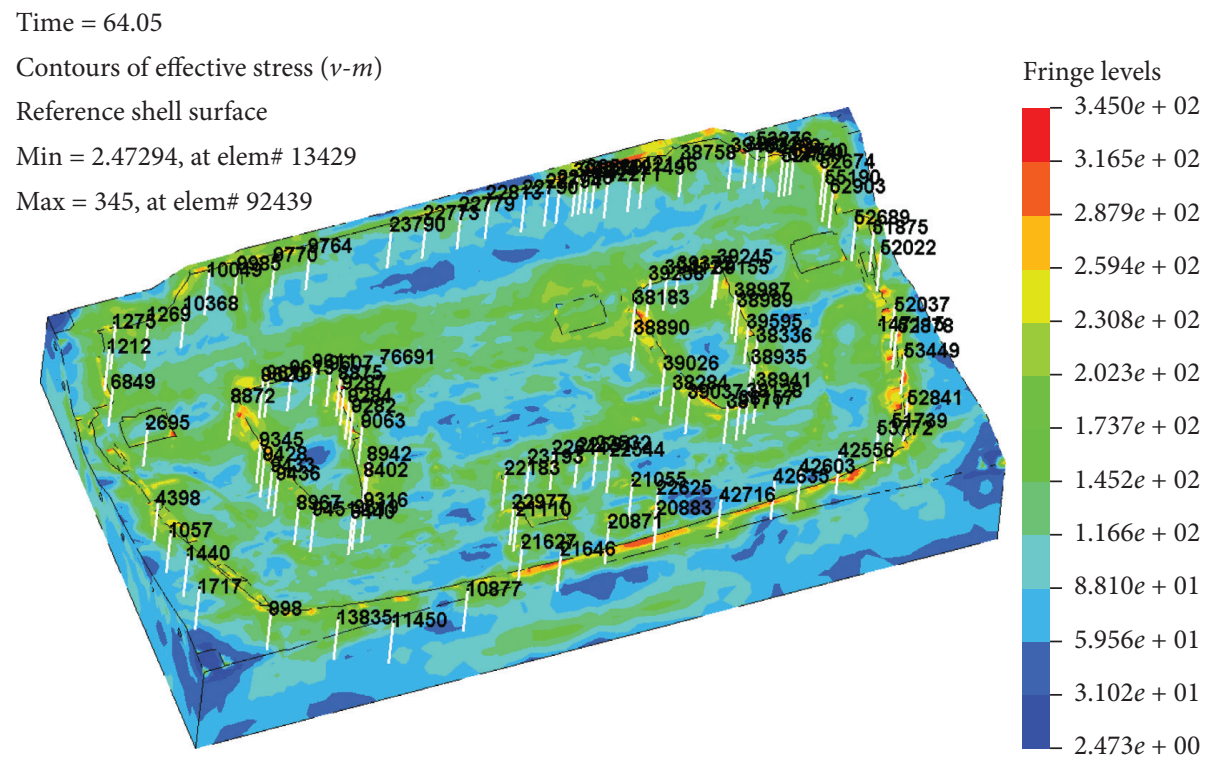

(a)

Contours of effective stress $(v-m)$

Reference shell surface

Min $=0.457014$, at elem\# 536714

Max $=344.093$, at elem\# 490044

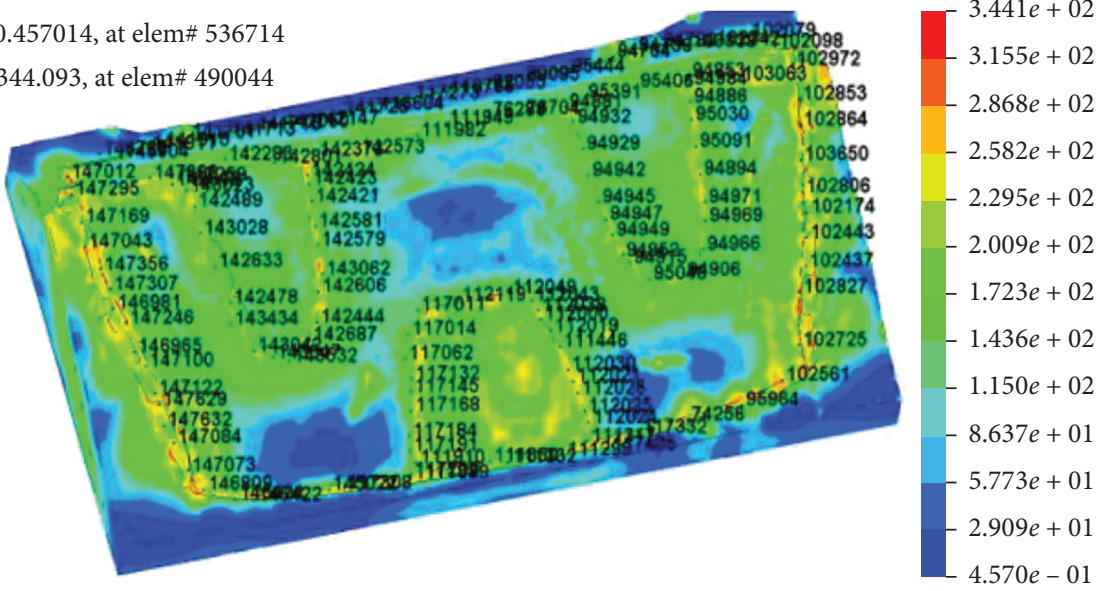

(b)

Figure 9: Derived node displacement result graph. (a) Nodal displacement results derived from the die. (b) Nozzle displacement results derived from punch.

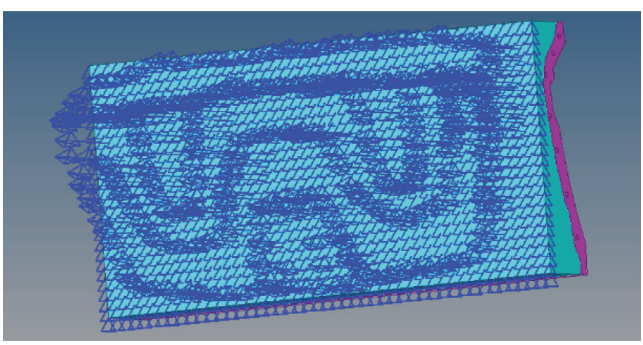

(a)

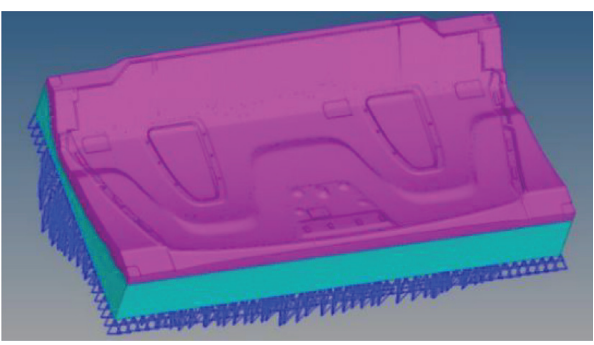

(b)

Figure 10: Boundary condition diagram of the upper die definition. (a) The upper die defines the boundary conditions. (b) The upper die defines the boundary conditions. 


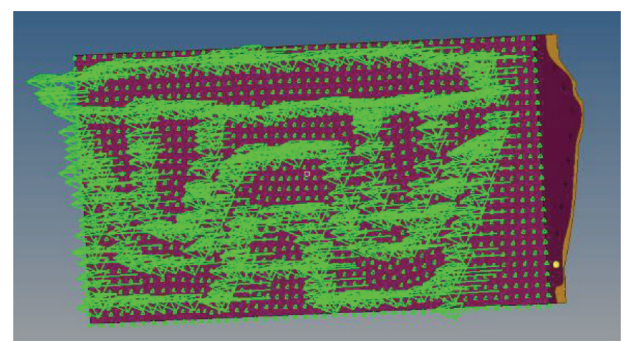

(a)

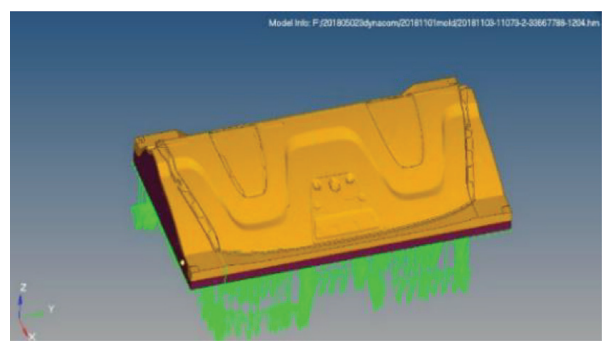

(b)

FIgURE 11: Boundary condition diagram of the lower die definition. (a) The lower die defines the boundary conditions. (b) The lower die defines the boundary conditions.

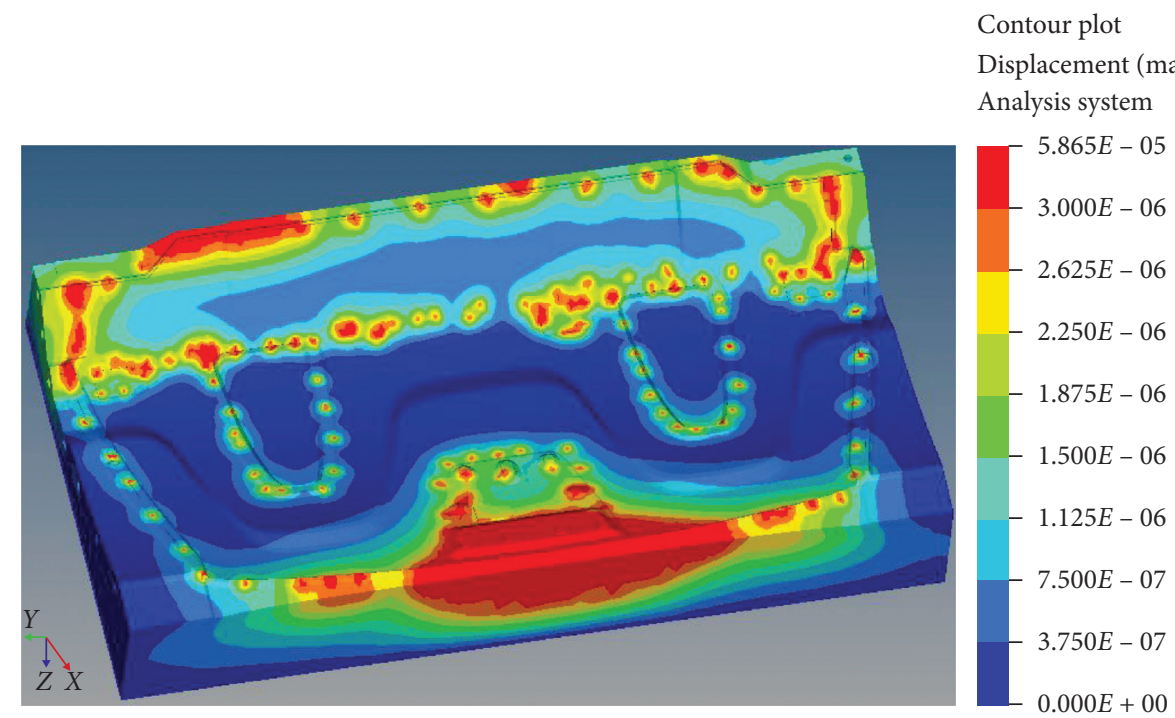

$\operatorname{Max}=5.865 E-05$

Grids 58850

Min $=0.000 E+00$

Grids 16971

(a)

Contour plot

Element stresses

(2D \& 3D)(vonMises)

Analysis system
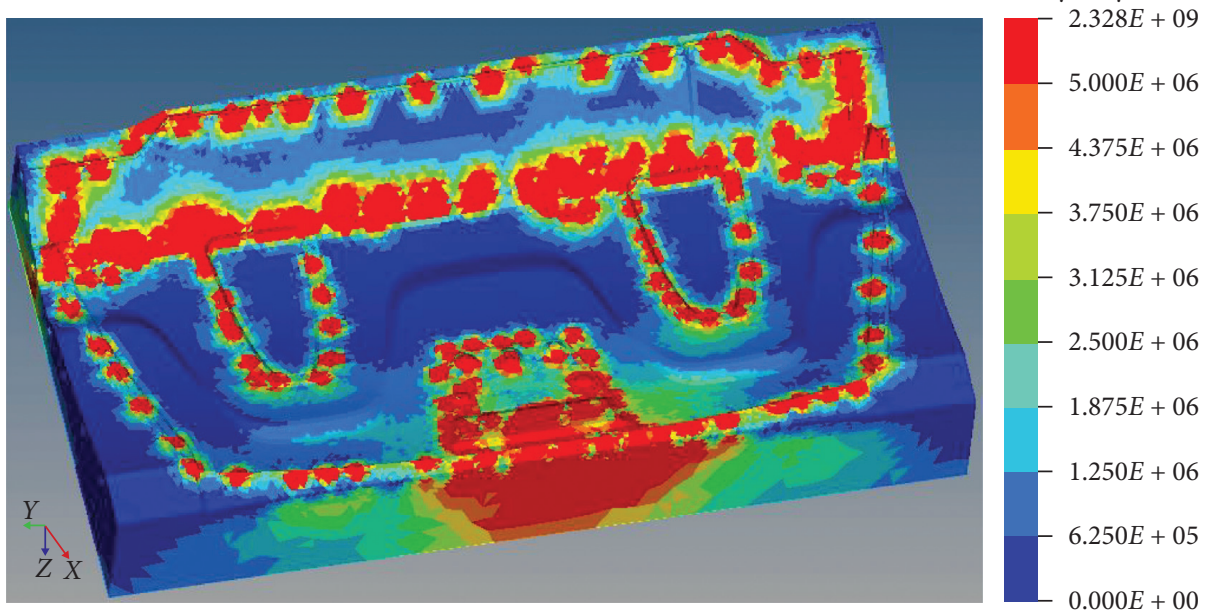

$\operatorname{Max}=2.328 E+09$

3D 360075

Min $=0.000 E+00$

3D 454673

(b)

Figure 12: Continued. 


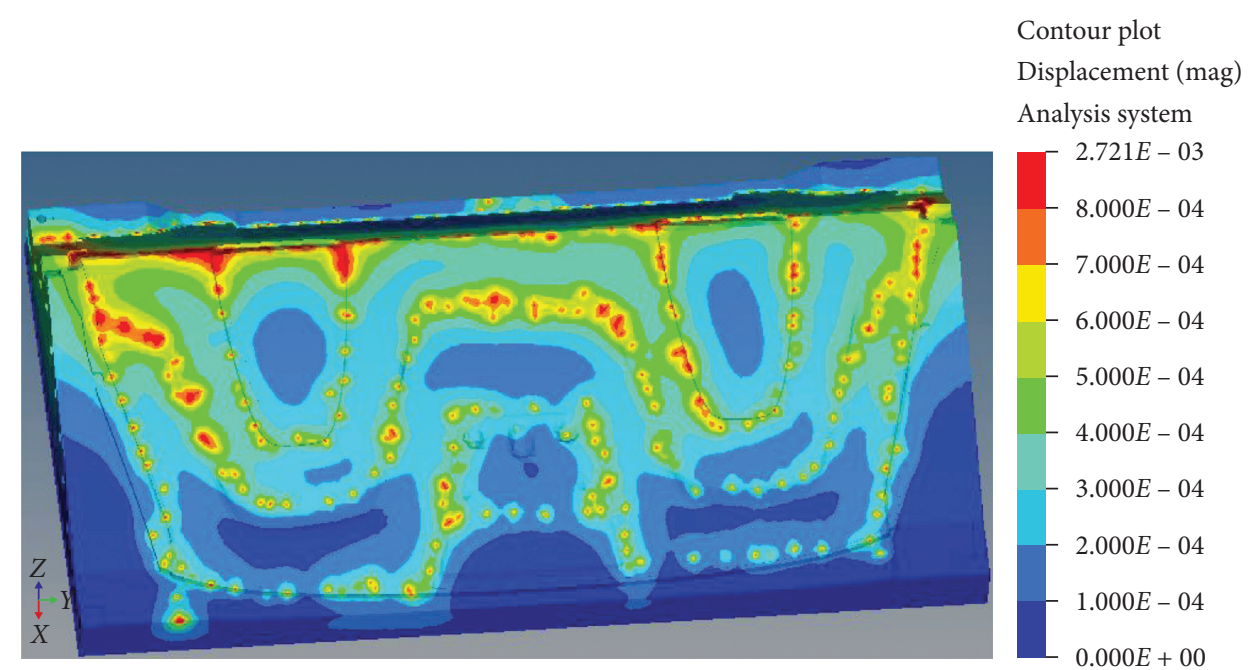

$\operatorname{Max}=2.721 E-03$

Grids 16134

Min $=0.000 E+00$

Grids 76670

(c)

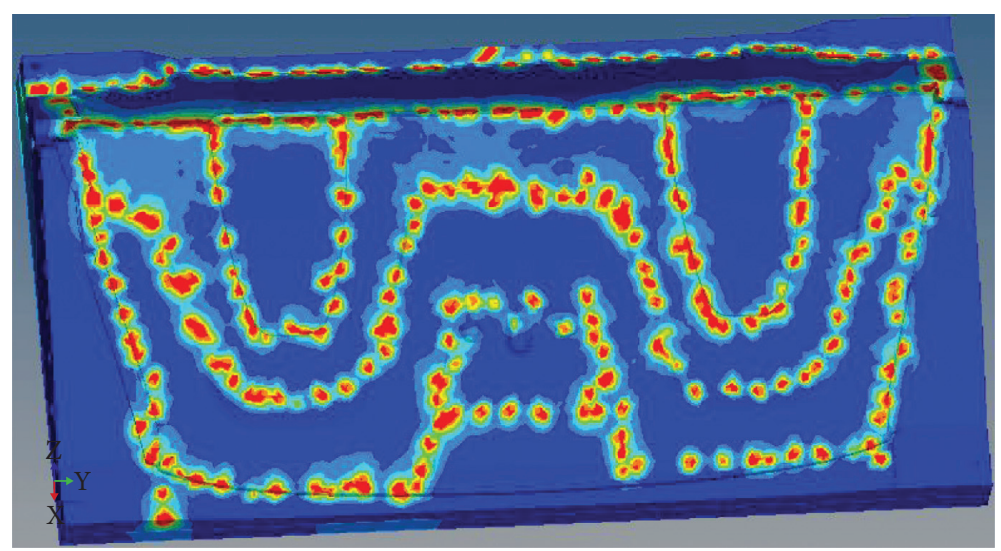

Contour plot

Element stresses

(2D \& 3D)(vonMises)

Analysis system

Simple average

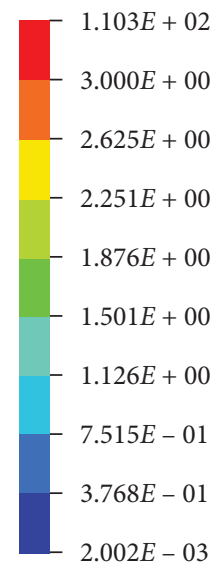

$\operatorname{Max}=1.103 E+02$

Grids 67460

$\operatorname{Min}=2.002 E-03$

Grids 64993

(d)

FIgURe 12: Preliminary calculation results. (a) Calculation result of upper die displacement. (b) Calculation result of upper mold equivalent stress. (c) Calculation result of lower die displacement. (d) Calculation result of equivalent stress of lower die.

4.2.3. Redesign of the Convex and Concave Mold Structure. According to the topological optimization of the optimal path of the material distribution, the topological shape of the model can be obtained. Through the OptiStruc-OSSmooth program, the IGES general CAD file is exported and fed back to CATIA. The CATIA software is used to reverse the convex and concave mold structure to obtain the topology. Figure 14 presents the optimized convex-concave structure.
By optimizing the topology of the convex and concave mold structure of the automobile coat rack compression mold, the optimized design results of the convex and concave mold structures of the automobile coat rack mold are obtained. After the CATIA volume measurement, the optimized design of the convex and concave mold can meet the strength and on the premise of stiffness, weight loss was $15.6 \%$. 


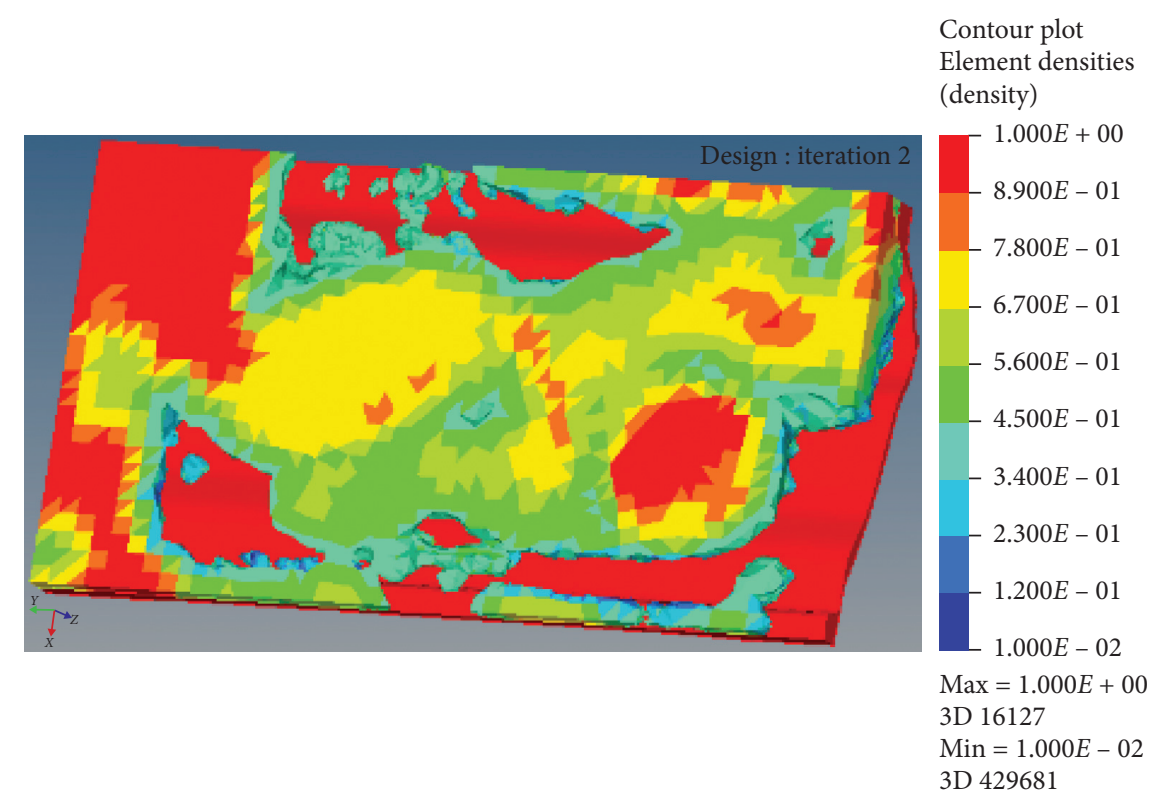

(a)

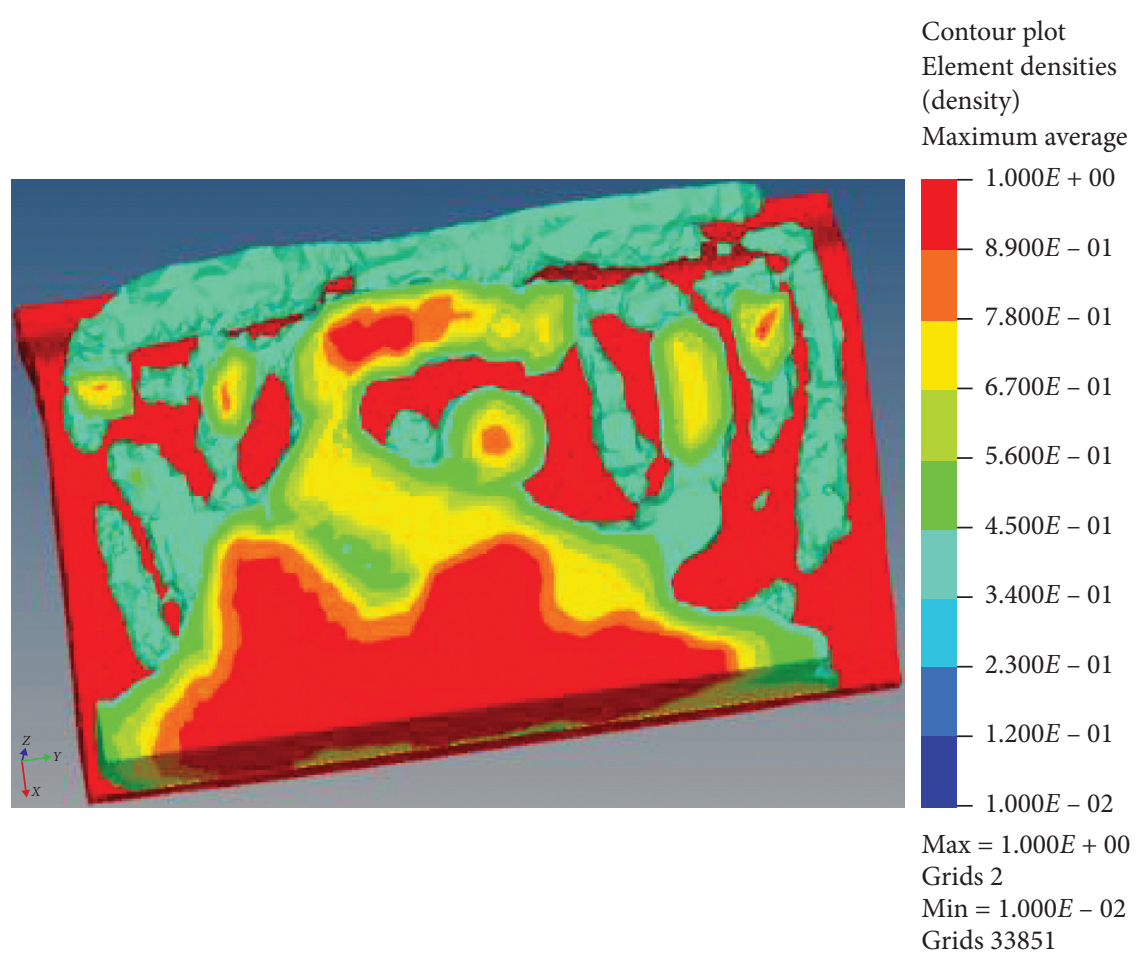

(b)

Figure 13: Topology optimization morphology. (a) Top mold topography. (b) Topology of the lower die.

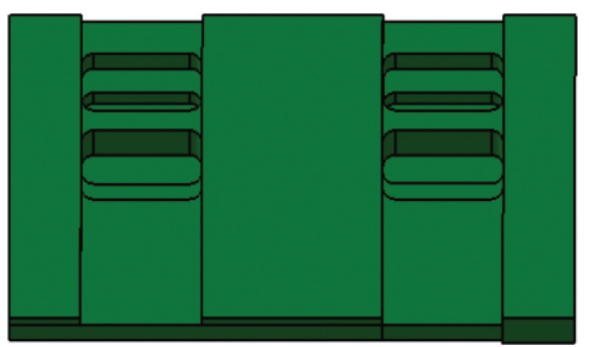

(a)

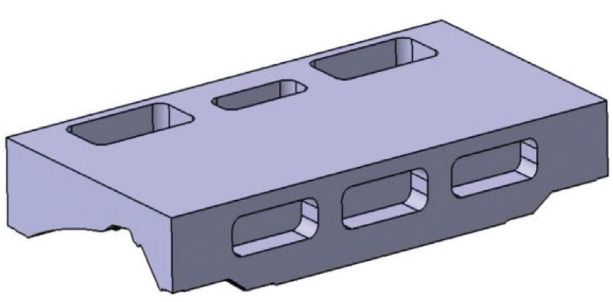

(b)

Figure 14: Optimal design of the convex and concave die. (a) Punch optimization design results. (b) Die optimization design results. 


\section{Conclusion}

The following conclusions are drawn from the present study:

(1) A mechanical model of the composite two-layer structure of the main body of the car coat rack is established. By solving the model, it is found that the main factors affecting the mechanical properties of the composite two-layer structure are the thickness of the PP glass fiber sheet and the content of glass fiber. The process parameters of the molding of the main body of the hat rack are prepared: the sheet preheating is performed by convection with hot air; the temperature of the hot air is $250^{\circ} \mathrm{C}$; the preheating time is $110 \mathrm{~s}$; the molding pressure is $13 \mathrm{MPa}$; and the holding time is $80 \mathrm{~s}$. Using the experimental method, the average shrinkage rate of the material is calculated to be $0.354 \%$, and the shrinkage rate of the solidification and cooling of the product is compensated by error compensation.

(2) Aiming at the current empirical design of mold designers, a lightweight design process for molding molds for interior parts is proposed. The LS-DYNA finite element program is used to simulate the molding process to obtain the actual working conditions. Under the stress concentration area of the mold, the nodal force information with large deformation is obtained. Therefore, the load mapping is used as the boundary condition of the next mold topology optimization.

(3) A mathematical model for SIMP material interpolation optimization of the male and female molds is established. Based on the variable density method, OptiStruct software is used to design the male and female molds of the main body of the automobile coat rack compression mold. The weight of the mold is reduced by $15.6 \%$, while ensuring the structural rigidity and strength of the mold.

\section{Data Availability}

The data used to support the findings of this study are included within the article.

\section{Disclosure}

This paper is part of the major projects of the "The University Synergy Innovation Program of Anhui Province (GXXT2019-004) and the project of the "Teaching Research Project of Anhui Education Department (2019jyxm0229).”

\section{Conflicts of Interest}

The authors declare that they have no conflicts of interest.

\section{References}

[1] J. Zheng, Y. Wei, and Z. Wei, "Rear window trim stiffness research on hatchback vehicle," Industrial Technology Innovation, vol. 3, no. 3, pp. 510-513, 2016.
[2] X. Guo, B. Ke, X. Liu, and D. Gong, "Reuse of waste PP glassfiber composite felt," Shanghai Textile Science \& Technology, vol. 42, no. 4, pp. 18-19, 2014.

[3] T. Miao, Y. Feng, and R. Zhang, "Multicomponent fibre composition process effect the properties of automotive coatrack," Journal of Wuhan Textile University, vol. 30, no. 3, pp. 30-34, 2017.

[4] R. Yu, Research on Key Technologies of Nonwoven Fabric Hot Molding, Soochow University, Suzhou, China, 2016.

[5] C. Shao, Research on Compression Molding Technology of Hatchback Door Plate with Glass Mat Reinforced Thermoplastics, Jilin University, Changchun, China, 2015.

[6] E. Demirci and A. R. Yildiz, "An investigation of the crash performance of magnesium, aluminum and advanced high strength steels and different cross-sections for vehicle thin walled energy absorbers," Materials Testing, vol. 60, no. 7-8, pp. 661-668, 2018.

[7] M. Li, P. Xue, M. Jia, and K. Chen, "Research development of processing technology of fiber-reinforced thermoplastic resin composites," China Plastics Industry, vol. 44, no. 11, pp. 5-11, 2016.

[8] J. Wang, C.-y. Fu, Y. Yu, J. Yanagimoto, and W. Zhu, "Effect of temperature on formability of glass mat reinforced thermoplastic sheets with ductile dummy sheets," Journal of Central South University, vol. 26, no. 4, pp. 779-786, 2019.

[9] M. Fellah, K. Draiche, H. M. S. Ahmed et al., "A novel refined shear deformation theory for the buckling analysis of thick isotropic plates," Structural Engineering and Mechanics, vol. 69, no. 3, pp. 335-345, 2019.

[10] J. Hartikainen, M. Lindner, T. Harmia, and K. Friedrich, "Mechanical properties of polypropylene composites reinforced with long glass fires and mineral fillers," Plastics, Rubber and Composites, vol. 33, no. 2-3, pp. 77-84, 2004.

[11] Y. Wang, Z. Zhu, L. Tang et al., "Research on the molding design and optimization of the molding process parameters of the automobile trunk trim panel," Advances in Materials Science and Engineering, vol. 2020, Article ID 5629717, 19 pages, 2020.

[12] Y. Zhu, H. Lu, and G. Dai, "Study on preheating technology for GMT thermoplastic sheet," China Plastics Industry, vol. 3, pp. 35-37, 2000.

[13] M. J. Song, K. Kwon-Hee, and H. Seok-Kwan, "Simulationbased optimization of cure cycle of large area compression molding for LED silicone lens," Advances in Materials Science and Engineering, vol. 2015, Article ID 573076, 11 pages, 2015.

[14] E. Demirci and A. R. Y1ldız, "An experimental and numerical investigation of the effects of geometry and spot welds on the crashworthiness of vehicle thin-walled structures," Materials Testing, vol. 60, no. 6, pp. 553-561, 2018.

[15] V. Goodship, I. Brzeski, B. M. Wood et al., "Gas-assisted compression moulding of recycled GMT: effect of gas injection parameters," Journal of Materials Processing Technology, vol. 214, no. 3, pp. 515-523, 2014.

[16] H. Li, Research on Topology Optimization Methods of Continuum Structure Based on Variable Density Method, Huazhong University of Science and Technology, Wuhan, China, 2011.

[17] S. V. Patankar, Numerical Heat Transfer and Fluid Flow, CRC Press, Boca Raton, FL, USA, 1980.

[18] LS-DYNA, Keyword User's Manual, Material Models, II, Livermore Software Technology Corporation (LSTC), Livermore, CA, USA, 2014.

[19] M. Stolpe and K. Svanberg, "An alternative interpolation scheme for minimum compliance topology optimization," 
Structural and Multidisciplinary Optimization, vol. 22, no. 2, pp. 116-124, 2001.

[20] D. Yan, W. Liu, G. Huang, and S. Xu, "Design study for composites autoclave forming mould," Aeronautical Manufacturing Technology, vol. 7, pp. 49-52, 2012.

[21] B. S. Lazarov, F. Wang, and O. Sigmund, "Length scale and manufacturability in density-based topology optimization," Archive of Applied Mechanics, vol. 86, no. 1-2, pp. 189-218, 2016.

[22] O. Sigmund and K. Maute, "Topology optimization approaches," Structural and Multidisciplinary Optimization, vol. 48, no. 6, pp. 1031-1055, 2013.

[23] A. Rietz, "Sufficiency of a finite exponent in SIMP (power law) methods," Structural and Multidisciplinary Optimization, vol. 21, no. 2, pp. 159-163, 2001.

[24] Q. Liu and X. Hou, "Structure topology optimization design of vehicle parts based on HyperMesh/OptiStruct," Equipment Manufacturing Technology, vol. 10, pp. 42-44, 2008. 